\title{
Endothelial Cell Synthesis of von Willebrand Antigen II, von Willebrand Factor, and von Willebrand Factor/von Willebrand Antigen II Complex
}

David R. McCarroll, Eugene G. Levin, and Robert R. Montgomery

The Blood Center of Southeastern Wisconsin, Inc., and Department of Pediatrics, The Medical College of Wisconsin, Milwaukee, Wisconsin 53233; and Departments of Basic and Clinical Research, Scripps Clinic and Research Foundation,

La Jolla, California 92037

\begin{abstract}
von Willebrand antigen II (vW AgII) and von Willebrand factor (vWf) are immunochemically distinct proteins that are deficient in the plasma and platelets of patients with severe von Willebrand's disease. Normal human umbilical vein endothelial cells were cultured in the presence of $\left[{ }^{35}\right.$ S $]$ methionine. Crossed immunoelectrophoresis of endothelial cell supernates and detergent-solubilized endothelial cells demonstrated specific incorporation of the $\left[{ }^{35}\right.$ S]methionine into $\mathrm{vW}$ AgII. Furthermore, when endothelial cells were lysed in the presence of proteolytic inhibitors, a second, less anodal peak was identified on crossed immunoelectrophoresis. This peak represented a complex of $\mathrm{vW}$ AgII and $\mathrm{vWf}$ and demonstrated a reaction of complete identity with the $\mathrm{vW}$ AgII immunoprecipitate. When plasma, serum, or platelets were evaluated by crossed immunoelectrophoresis, this "complex" peak was not present. When antibodies to vWf, fibronectin, or fibrinogen were present in the first dimension of crossed immunoelectrophoresis, only the antibodies to vWf removed the complex. Radioiodinated polyclonal and monoclonal antibodies to vWf also localized vWf to this complex. Under reducing conditions, sodium dodecyl sulfatepolyacrylamide gel electrophoresis of $\left[{ }^{35}\right.$ S $]$ methionine-labeled immunoprecipitates indicated that the molecular weight of $\mathrm{vW}$ AgII is 98,000 and that vWf was present as two species of 220,000 and 260,000 mol wt, respectively. Immunofluorescent microscopy of endothelial cells demonstrated colocalization of vW AgII and vWf in endothelial cells with intense immunostaining of the same subcellular granules.
\end{abstract}

\section{Introduction}

von Willebrand's disease is characterized by a deficiency or structural abnormality in von Willebrand factor $(\mathrm{vWf})^{1}(1-3)$. A second protein, von Willebrand antigen II (vW AgII), is also deficient or absent in von Willebrand's disease (4). While both $\mathrm{vWf}$ and $\mathrm{vW}$ AgII have not been shown to share antigenic

Dr. Montgomery is an Established Investigator of the American Heart Association. Address reprint requests to Dr. Montgomery, The Blood Center of Southeastern Wisconsin, Inc., Milwaukee, WI 53233.

Received for publication 5 March 1984 and in revised form 3 December 1984

1. Abbreviations used in this paper: DDAVP, 1-desamino-8-D-argininevasopressin; PMSF, phenylmethylsulfonylfluoride; SDS-PAGE, sodium dodecyl sulfate-polyacrylamide gel electrophoresis; vW AgII, von Willebrand antigen II; vWf, von Willebrand factor.

J. Clin. Invest.

(c) The American Society for Clinical Investigation, Inc. 0021-9738/85/04/1089/07 \$1.00

Volume 75, April 1985, 1089-1095 determinants $(4,5)$, their levels in plasma are linearly associated (6). vWf and vW AgII are both synthesized by cultured human endothelial cells and released concomitantly after in vivo stimulation with 1-desamino-8-D-arginine-vasopressin (DDAVP) (7). Both proteins are also found in platelets and are released together after platelet activation (8).

$\mathrm{vWf}$ is a glycoprotein that circulates in plasma as a series of high molecular weight multimers (1-3) and mediates the adhesion of platelets to exposed subendothelium (9). These multimers are comprised of 220,000 -mol-wt subunits that are held together by disulfide bonds and range in molecular weights up to $20 \times 10^{6}$. vWf is measured antigenically as von Willebrand antigen or Factor-VIII-related antigen (10) and functionally as the cofactor that mediates platelet aggregation in the presence of the antibiotic ristocetin (11). vWf is synthesized in endothelial cells (12-14) and megakaryocytes (15). Studies of vWf synthesized in cultured human umbilical vein endothelium indicate processing that includes not only glycosylation but also cleavage of a 260,000 -mol-wt precursor molecule into the 220,000 -mol-wt vWf subunit (14). Intracellularly, vWf appears to be present as a series of multimers with molecular weights equivalent to those of normal plasma, reaching at least $10 \times 10^{6} \mathrm{~mol} \mathrm{wt}(16)$. Most of the protein, however, appears to be present in the dimeric (14) or tetrameric (16) form. vWf has demonstrated in Weibel-Palade bodies (17), although the significance of this subcellular localization is not well understood. vWf secreted into the culture fluid of endothelial cells possesses the multimeric conformations typical of plasma $\mathrm{vWf}(14,16)$.

$\mathrm{vW}$ AgII is a second protein described as deficient in von Willebrand's disease (4). vW AgII is found in plasma and platelets, with approximately two-thirds circulating in platelets (8). It is released from platelets during activation by thrombin, ADP, or collagen and is present at increased levels in the plasma of individuals with syndromes associated with platelet activation, such as disseminated intravascular coagulation and hemolytic uremic syndrome (8). vW AgII shows an immunochemical reaction of nonidentity with $\mathrm{vWf}(4)$ by crossed immunoelectrophoresis (5). Thus an enigma is presented: two distinct proteins are both absent in a single genetic disorder, and yet they are found in amounts that are linearly correlated in the circulation of normal individuals and of individuals with classic von Willebrand's disease. Their potential relationship, therefore, may be pertinent to the pathophysiology of von Willebrand's disease. This study was undertaken to characterize vW AgII more fully and to determine the association between vW AgII and vWf within the endothelial cell.

\section{Methods}

Materials. Unless otherwise noted, supplies and reagents used in endothelial cell culture were purchased from Gibco Laboratories, 
Grand Island, NY. Other materials included Type I collagenase (Worthington Biochemicals Corp., Freehold, NJ), fetal calf serum (Biocell, Carson, CA), bovine pituitaries (Pel-Freeze Biologicals, Rogers, AR), $\left[{ }^{35} \mathrm{~S}\right]$ methionine $(800 \mathrm{mCi} / \mathrm{mM}$ sp act; Amersham Corp., Arlington Heights, IL), fluorescein- and rhodamine-conjugated, preabsorbed antibodies to mouse and rabbit IgG (Tago Inc., Burlingame, CA), Hemofil (Hyland Laboratories, Costa Mesa, CA), protein A Sepharose 4B (Pharmacia Fine Chemicals, Div. of Pharmacia Inc., Piscataway, NJ), Biogel A15 (Bio-Rad Laboratories, Richmond, CA), SeaKem Agarose ME (FMC Corporation, Marine Colloids Division, Springfield, NJ), and nonionic detergent NP40 (Particle Data, Inc., Elmhurst, IL). All other reagents were purchased from commercial sources and were of the best available grade.

Endothelial cell cultures. Normal human umbilical vein endothelium was cultured by methods previously described (18). Complete medium consisted of RPMI 1640 with $20 \%$ fetal calf serum augmented with $5.9 \mathrm{~g} /$ liter Hepes buffer, $2 \mathrm{mM}$ L-glutamine, $100 \mathrm{U} / \mathrm{ml}$ penicillin, and $100 \mathrm{U} / \mathrm{ml}$ streptomycin. Umbilical cords $<24 \mathrm{~h}$ old were cleaned, and the veins rinsed free of blood with lactated Ringer's solution. Cords were clamped and filled with $25 \mathrm{U} / \mathrm{ml}$ Type I collagenase. Enzymatic digestion was allowed to proceed at $37^{\circ} \mathrm{C}$ for $15 \mathrm{~min}$. Cells were removed from the collagenase by centrifugation at $1,000 \mathrm{~g}$ for 5 min and then resuspended in complete medium. Cells from several cords were pooled and distributed at $1-5 \times 10^{4}$ cells $/ \mathrm{cm}^{2}$ onto $75 \mathrm{~cm}^{2}$ flasks precoated with gelatin. Cells were grown at $37^{\circ} \mathrm{C}$ in $5 \% \mathrm{CO}_{2}$ and reached confluence within $5 \mathrm{~d}$.

Secondary cultures were derived by splitting primary cultures $1: 3$. Complete medium was removed from confluent cultures and the cells "trypsinized" with $10 \mathrm{ml}$ phosphate-buffered saline (PBS), pH 7.4, containing $500 \mathrm{mg}$ trypsin and $20 \mathrm{mg}$ EDTA. Cells were harvested by centrifugation and subcultured as described for primary cultures. Secondary cultures contained $100 \mu \mathrm{g} / \mathrm{ml}$ endothelial cell growth factor prepared as described elsewhere (19) from bovine pituitaries.

Metabolic labeling of cellular proteins was achieved by incubation of confluent cultures at $37^{\circ} \mathrm{C}$ for $4 \mathrm{~h}$ in serum-free RPMI 1640 that lacked methionine. Methionine was supplied as $200 \mu \mathrm{Ci}\left[{ }^{35} \mathrm{~S}\right]$ methionine/ $\mathrm{ml}$. All radiolabeled cells were washed three times in RPMI 1640 supplemented with a 100 -fold excess of unlabeled methionine (150 $\mathrm{mg} / \mathrm{liter}$ ) and twice in lactated Ringer's solution immediately before harvesting. Labeled cells were harvested by lysing, in situ, in $0.1 \mathrm{M}$ Tris $\mathrm{HCl}, \mathrm{pH} 8.6$, containing $1 \mathrm{mM}$ phenylmethylsulfonylfluoride (PMSF) in $5 \mathrm{mM}$ EDTA, $1 \% \mathrm{NP40}, 0.15 \mathrm{M} \mathrm{NaCl}$, and $1 \mathrm{mM}$ iodoacetic acid. Endothelial cell lysate or culture supernate was centrifuged at $12,000 \mathrm{~g}$ and stored at $-80^{\circ} \mathrm{C}$.

Antisera. Antisera monospecific for $\mathrm{vW}$ AgII were prepared as described, using $\mathrm{vW}$ AgII derived from outdated normal human platelets (6). Absorption of antisera with plasma from an individual with severe von Willebrand's disease (no detectable $\mathrm{vW}$ AgII or vWf) yielded antisera that gave a single precipitin arc on crossed immunoelectrophoresis (6).

The IgG fraction of antisera to vW AgII was isolated after ammonium sulfate precipitation, DEAE ion exchange chromatography, and immunopurification on a column of Sepharose 4B with which $v W$ AgII had been coupled using cyanogen bromide (5).

Antisera to human fibronectin or fibrinogen were used in crossed immunoelectrophoresis (Fig. 6). These antisera were the generous gifts of Dr. M. Mosesson and Dr. D. Amrani, Mount Sinai Medical Center, Milwaukee, WI. Polyspecific rabbit antisera to vWf, immunopurification of antibodies to vWf by affinity chromatography, and methods used in obtaining monoclonal antibodies to vWf are described elsewhere $(5,20)$.

Crossed immunoelectrophoresis. Crossed immunoelectrophoresis was performed as previously described (5) using $0.9 \%$ agarose in buffer containing per liter $7.2 \mathrm{~g}$ Tris base, $3.0 \mathrm{~g}$ barbituric acid, and $13.1 \mathrm{~g}$ sodium barbital, $\mathrm{pH}$ 8.5. First dimension electrophoresis of up to six $100-\mu 1$ samples was performed on a single platelet at $4 \mathrm{~mA} / \mathrm{cm}$ at room temperature. Lanes containing antigen were excised and transferred to separate plates for second dimension electrophoresis into agarose containing the appropriate antibodies. Gels were washed in several changes of $1 \% \mathrm{NP} 40,10 \mathrm{mM}$ benzamidine $\mathrm{HCl}, 0.15 \mathrm{M} \mathrm{NaCl}$, pressed, dried, and autoradiographed at $-80^{\circ} \mathrm{C}$ with Kodak X-Omat RP film (5). Radiolabeling of immunoprecipitates formed on crossed immunoelectrophoresis was done by $(a)$ using endogenously labeled endothelial cell proteins (7); $(b)$ forming immunoprecipitates with antibodies with which ${ }^{125}$ I had been coupled, using the chloramine $T$ method (21); or $(c)$ using ${ }^{125}$ I-labeled plasma protein that had been partially purified on Biogel A15 as described (5).

Immunofluorescent labeling of endothelial cells. Intracellular localization of vWf and vW AgII was determined by double label indirect immunofluorescence. Cells were grown on $4 \mathrm{~cm}^{2}$ glass coverslips precoated with fibronectin. Purified fibronectin was the generous gift of Dr. D. Amrani and Dr. M. Mosesson, Mount Sinai Medical Center, Milwaukee, WI. Cells were fixed and permeabilized with $5 \%$ acetic acid in $95 \%$ ethanol. Incubations with primary and secondary antisera were for $30 \mathrm{~min}$ at $4^{\circ} \mathrm{C}$, followed by rinsing in PBS $(0.05 \mathrm{M}$ phosphate, $0.15 \mathrm{M} \mathrm{NaCl}, \mathrm{pH}$ 7.4). Antibodies to $\mathrm{vWf}$ were murine monoclonals (AVW1, AVW2, and AVW3) (20). The antibodies to vW AgII were immunopurified from polyclonal rabbit IgG as described above. To further remove any antibody to vWf, the immunopurified IgG was absorbed with $0.2 \mathrm{vol} \mathrm{vWf}$ from void-volume fractions of purified vWf, gel-filtered over $4 \%$ agarose. Absorption was overnight at $4^{\circ} \mathrm{C}$.

Fluorescein-conjugated goat anti-rabbit IgG was the second antibody used to label polyclonal rabbit IgG directed against vW AgII. Rhodamine-conjugated rabbit anti-mouse IgG was the second antibody used to label murine monoclonal IgG directed against $\mathrm{vWf}$. For the double label experiments presented here, antibodies to both antigens were added to the same cell preparation. Respective second antibodies were likewise added to the same cells. Fluorescein was visualized by excitation at $489 \mathrm{~nm}$; rhodamine at $554 \mathrm{~nm}$. Both conjugated second antisera were preabsorbed against interspecies cross-reacting material.

Molecular weight estimations using sodium dodecyl sulfate-polyacrylamide gel electrophoresis (SDS-PAGE). SDS polyacrylamide gels were prepared using standard methods as described previously (22). Immunoprecipitates were obtained from crossed immunoelectrophoresis gels or from antigen/antibody mixtures immobilized on protein A coupled with Sepharose 4B $(14,23)$. Immunoprecipitates generated in agarose by crossed immunoelectrophoresis were washed in cell lysis buffer that contained proteolytic inhibitors and autoradiographed at $4^{\circ} \mathrm{C}$. The precipitin arcs were cut from the gels using the autoradiographs as templates. The excised immunoprecipitates were transferred into $100 \mu \mathrm{l}$ SDS-PAGE loading buffer that contained $0.1 \mathrm{M}$ Tris, pH 6.8, $2 \%$ SDS, $20 \%$ glycerol, $0.1 \%$ bromophenol blue, and for reduced samples, $20 \% \beta$-mercaptoethanol. Samples in loading buffer were melted in boiling water and immediately layered on SDS-PAGE gels (23).

Immunoprecipitates were isolated from antigen/antibody mixtures using protein A Sepharose 4B. Antigen/antibody mixtures were incubated for $30 \mathrm{~min}$. at room temperature and then added to protein $A$ Sepharose 4B for $1 \mathrm{~h}$. PMSF was added to each washing buffer immediately before use. Protein A Sepharose beads were washed before use in $0.1 \mathrm{M}$ phosphate buffer, $\mathrm{pH} 8.6$, containing $0.15 \mathrm{M} \mathrm{NaCl}, 0.1 \%$ bovine serum albumin (BSA), $0.5 \% \mathrm{NP} 40$, and $0.02 \% \mathrm{NaN}_{3}$. After coupling protein $\mathrm{A}$ with antigen/antibody complexes, beads were washed in 100-fold excesses of the following buffers. The initial wash was in $1.0 \mathrm{M} \mathrm{NaCl}$ consisting of $0.1 \% \mathrm{NP} 40$ buffered to $\mathrm{pH} 8.6$ with $0.05 \mathrm{M}$ Tris $\mathrm{HCl}$. The next seven washes were in the PBS-BSA-NP40

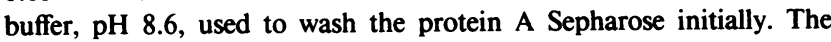
next two washes were in $0.1 \mathrm{M} \mathrm{NaCl}$ consisting of $0.1 \% \mathrm{NP40}$ buffered to $\mathrm{pH} 6.8$ with $0.5 \mathrm{M}$ Tris $\mathrm{HCl}$, followed by two washes in $0.5 \mathrm{M}$ $\mathrm{LiCl}$, and then two washes in deionized water. This regime resulted in no further release of radioactivity into washing buffers. Washed immunoprecipitins bound to protein $\mathrm{A}$ beads were subsequently prepared for SDS-PAGE as described for immunoprecipitates contained in agarose.

Ultracentrifugation. Samples of $100 \mu \mathrm{l}$ of endogenously labeled endothelial cell lysates were centrifuged for $20 \mathrm{~min}$ at $100,000 \mathrm{~g}$ at 
$4^{\circ} \mathrm{C}$ in $4.8 \times 19.9 \mathrm{~mm}$ cellulose nitrate tubes, using an airfuge (Beckman Instruments, Inc., Fullerton, CA). Three aliquots of $33 \mu \mathrm{l}$ were removed sequentially from the top, using a micropipette, taking care that no mixing occurred. Samples were analyzed by crossed immunoelectrophoresis and compared with uncentrifuged lysates.

\section{Results}

Molecular weight of $v W A g I I$ and endothelial cell $v W f$. The molecular weight of $\mathrm{vW}$ AgII was estimated using SDS-PAGE for samples of both endothelial cell protein and plasma protein isolated from commercial concentrate. vW AgII from both sources demonstrated a molecular weight of 74,000 nonreduced and $92-98,000$ reduced. The reduced and nonreduced molecular weights of plasma vW AgII are shown in Fig. 1. The molecular weights of endothelial cell vW AgII are shown in Fig. 2. The larger molecular weight identified upon reduction suggests significant intramolecular disulfide bonding.

vWf immunoprecipitated with monoclonal antibodies from endothelial cell lysates yielded two bands of ${ }^{35} \mathrm{~S}$-labeled vWf. Molecular weights of 220,000 and 260,000 were determined for these subunits (data not shown). These data are in agreement with estimates for the precursor $(260,000 \mathrm{~mol} \mathrm{wt})$ and subunit forms previously described for vWf $(13,14)$.

Identification of an endothelial cell complex between $v W$ AgII and $v W f$. The characteristic reaction of nonidentity that is seen for vW AgII and vWf derived from plasma, serum, platelet releasate, and platelet lysate (in the presence of PMSF alone or PMSF and leupeptin $[20 \mu \mathrm{g} / \mathrm{ml}])(4,5)$ is also seen with endothelial cell supernate (data not shown). In contrast to this pattern, the results of crossed immunoelectrophoresis of $\left[{ }^{35} \mathrm{~S}\right]$ methionine-labeled endothelial cell lysate against antisera monospecific for vW AgII is shown in Fig. 3. A second, less

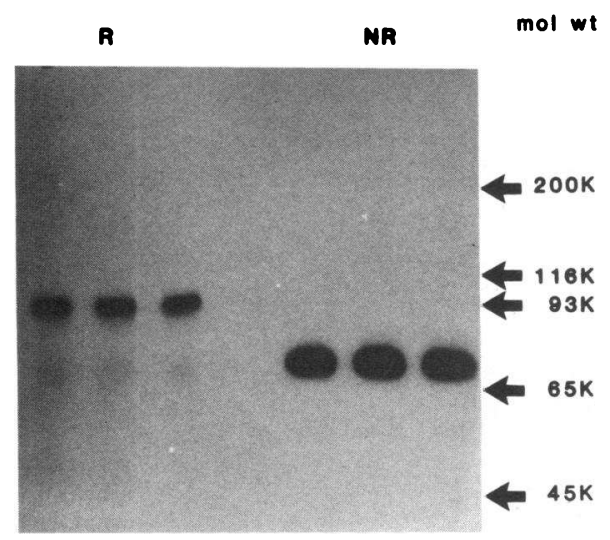

Figure 1. Molecular weight estimates of plasma vW AgII by SDSPAGE. vW AgII from three different commercial Factor VIII concentrates was partially purified by gel filtration through Biogel A15 and radioiodinated. Labeled vW AgII was subjected to crossed immunoelectrophoresis into unlabeled antisera to $\mathrm{vW}$ AgII. Immunoprecipitates were visualized by autoradiography, excised, and subjected to SDS-PAGE. Samples of vW AgII from the three commercial Factor VIII concentrates were electrophoresed in the presence (left lanes) or absence (right lanes) of $\beta$-mercaptoethanol. Molecular weight markers (arrows) were stained with Coomassie blue, and the radiolabeled vW AgII protein was detected by autoradiography. Molecular weight estimates for vW AgII are 98,000 reduced and 74,000 nonreduced, suggesting intramolecular disulfide bonding. $K, \times 1,000$; $R$, reduced; NR, nonreduced.

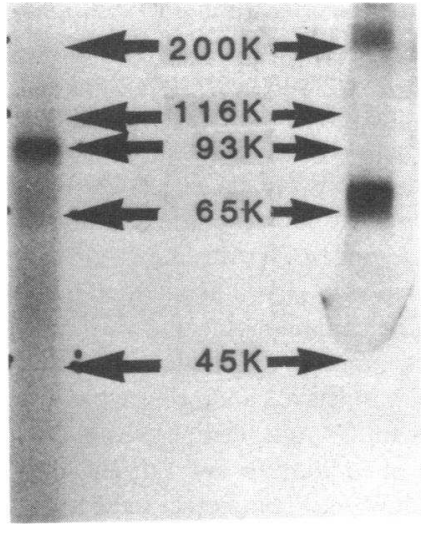

Figure 2. Molecular weight estimation of endothelial cell $\mathrm{vW}$ AgII. SDS-PAGE was performed as in Fig. 1. Endothelial cell proteins were endogenously labeled with

$\left[{ }^{35}\right.$ S $]$ methionine and the cell lysate subjected to crossed immunoelectrophoresis into unlabeled antisera to vW AgII, and then analyzed on an SDSPAGE in the presence (left lanes) or absence (right lanes) of $\beta$-mercaptoethanol. Molecular weight markers were visualized with Coomassie blue, while radiolabeled protein was

detected by autoradiography. Molecular weights for vW AgII of 92,000 reduced and 74,000 nonreduced were estimated and are in agreement with those obtained from plasma vW AgII. The upper band on the right of $>200,000 \mathrm{~mol} w \mathrm{w}$ is not $\mathrm{vWf}$ and its identity remains unknown. $\mathrm{K}, \times 1,000$.

anodic peak is present that shows an immunochemical reaction of complete identity with vW AgII. This less anodic peak can be distinguished from $\mathrm{vWf}$ after antisera to $\mathrm{vWf}$ is incorporated into the upper third of the crossed immunoelectrophoresis gel. The results showing $\mathrm{vW}$ AgII complex and vWf precipitin arcs are shown in Fig. 4. The vWf that is not complexed to vW AgII reacts with the anti-vWf antibody present in the upper one-third of the gel.

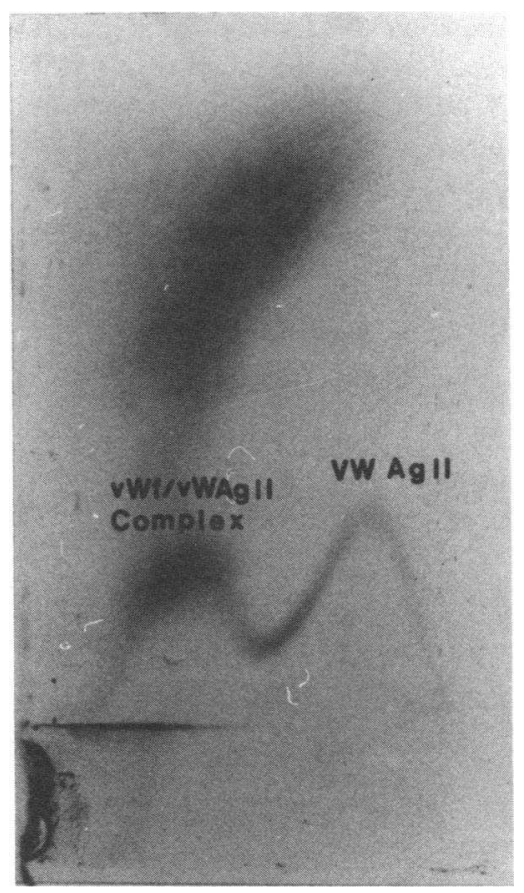

Figure 3. Crossed immunoelectrophoresis of endothelial cell lysate. Endogenously labeled endothelial cell lysate was analyzed using crossed immunoelectrophoresis. The second-dimension gel contained unlabeled antisera to $\mathrm{vW}$ AgII. Immunoprecipitates were visualized on an autoradiograph, which is presented in this figure. An immunochemical reaction of complete identity is seen between vW AgII and the less anodic peak. 


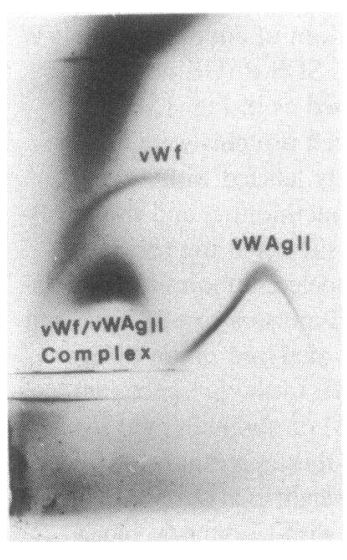

Figure 4. Crossed immunoelectrophoresis of endothelial cell lysate. Endogenously labeled endothelial cell lysate was analyzed as in Fig. 3. The autoradiograph is presented. Antiserum to $\mathrm{vW}$ AgII was present in the intermediate gel in the second dimension. Antiserum to $\mathrm{vWf}$ was present in an agarose strip placed anodally to the agarose containing the anti-vW AgII. Thus immunoprecipitation of free vWf was delayed and occurred anodally to vW AgII, demonstrating free $\mathrm{vWf}$ in addition to vW AgIl and the $\mathrm{vWf} / \mathrm{vW}$ AgII complex in these samples.

To demonstrate further that the complex in endothelial cells is comprised of both vWf and vW AgII antigenic determinants, we preincubated endothelial cell lysate with antisera monospecific for human fibrinogen, fibronectin, or vWf. The samples were then subjected to crossed immunoelectrophoresis, and the results are shown in Fig. 5. Only antisera to vWf removed the high-molecular-weight complex (hereafter termed $\mathrm{vWf} / \mathrm{vW}$ AgII complex), indicating that this complex contained $v W f$ epitopes, and that this reaction was specific since the other two antisera did not alter the vWf/vW AgII complex or vW AgII. This was further confirmed using nonradiolabeled endothelial cell lysate and radioiodinated monoclonal antibodies to vWf, termed AVW1, AVW2, and AVW3 (20). Radioiodinated monoclonal antibodies to $\mathrm{vWf}$ were specifically incorporated into both vWf and the vWf/vW AgII complex (Fig. 6) without labeling vW AgII. Of 14 monoclonal antibodies to vWf thus far tested, none shows cross-reactivity with vW AgII.

When washed platelets were lysed in the presence of PMSF and leupeptin, the vWf/vW AgII complex was not present on analysis by crossed immunoelectrophoresis (data not shown). Further, when endothelial cells were lysed in the absence of
PMSF and leupeptin, vWf/vW AgII complex was not stable and was lost from crossed immunoelectrophoresis patterns (Fig. 7). Plasma vWf and vW AgII do not exist as a complex regardless of whether protease inhibitors are present or not.

When endogenously labeled vWf/vW AgII complex was excised from crossed immunoelectrophoresis gels and analyzed by SDS-PAGE, vW AgII demonstrated a molecular weight of 98,000 . Although molecular weight estimates above 200,000 decrease in accuracy, vWf demonstrated a molecular weight of $\sim 30-50,000$ more than that of plasma $\mathrm{vWf}$ when the two forms of this antigen were reduced and compared on the same gel by SDS-PAGE (Fig. 8).

Intracellular localization of $v W A g I I$ in the endothelial cell. Endothelial cells were permeabilized and labeled with rabbit antisera, monospecific for $\mathrm{vW}$ AgII, and monoclonal mouse IgG, specific for vWf. Fluorescein-conjugated second antibody demonstrated significant fluorescent labeling of $\mathrm{vW}$ AgII in the perinuclear region and strong labeling of organelles previously identified as Weibel-Palade bodies (17) (Fig. $9 A$ ). Rhodamine-conjugated second antibody displayed an identical pattern for labeling of $\mathrm{vWf}$ in these organelles, indicating colocalization of these two antigens (Fig. $9 \mathrm{~B}$ ).

Samples of endothelial cell lysate were ultracentrifuged to determine whether the $\mathrm{vWf} / \mathrm{vW}$ AgII complex might be insolubilized organelle material as seen in immunofluorescentlabeled cells. Ultracentrifugation of $100 \mu \mathrm{l}$ of endothelial cell lysate at $100,000 \mathrm{~g}$ did not alter the crossed immunoelectrophoresis pattern of $\mathrm{vWf}, \mathrm{vW}$ AgII, or $\mathrm{vWf} / \mathrm{vW}$ AgII complex. Neither the quantity nor the mobility of vWf/vW AgII complex differed in samples taken from the top or the bottom of the centrifuge tube. Thus the vWf/vW AgII complex was not caused by the electrophoresis of subcellular particulate matter.

\section{Discussion}

These data show that within the endothelial cell, vW AgII forms a soluble complex with vWf (Fig. 3). Crossed immuno-
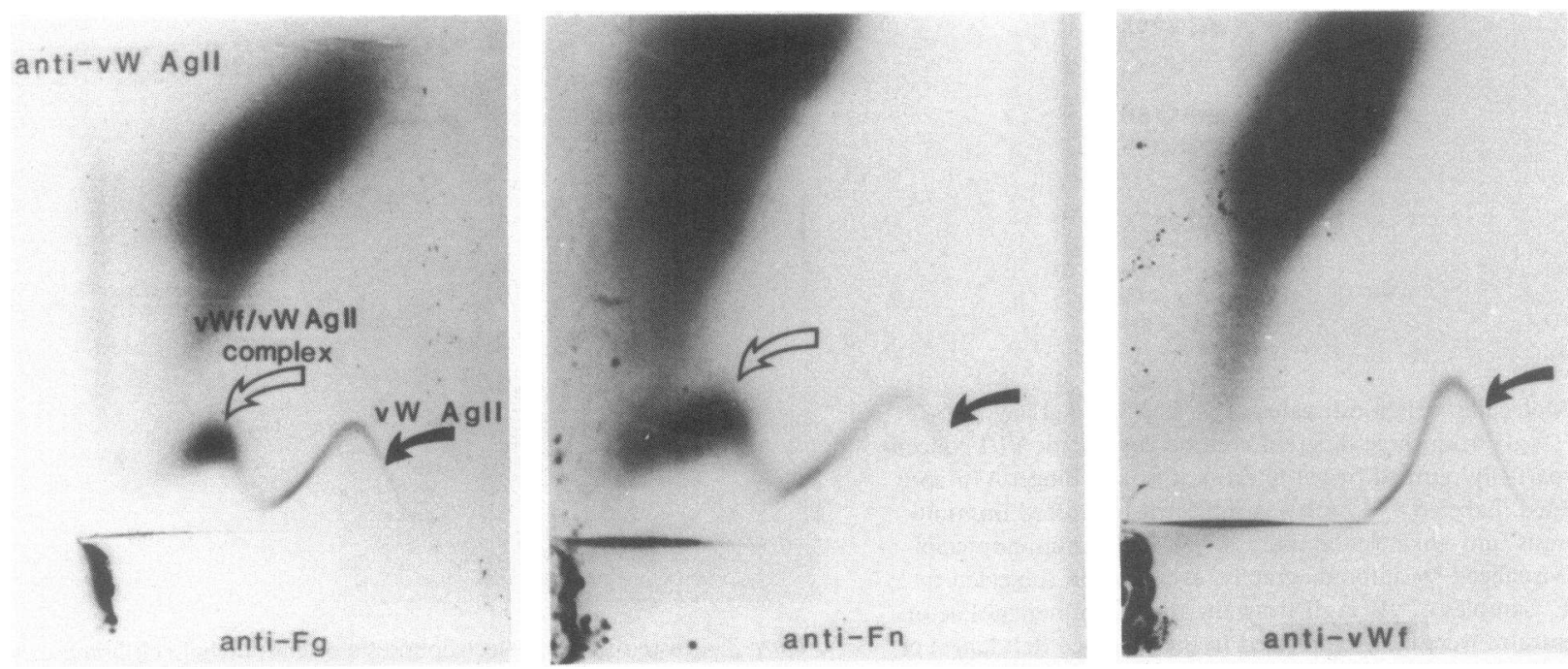

Figure 5. Inhibition of the vWf/vW AgII complex entry into the first dimension of crossed immunoelectrophoresis. Antisera to large adherent glycoproteins, fibrinogen $(\mathrm{Fg})$, fibronectin $(\mathrm{Fn})$, or $\mathrm{vWf}$ were mixed with endogenously labeled endothelial cell lysate before separation of proteins in the first dimension. Crossed immunoelectropho- resis was performed as in Fig. 4, with autoradiographs presented in the composite. Antisera to vWf, but not Fg or Fn, completely inhibited the entry of $\mathrm{vWf} / \mathrm{vW}$ AgIl complex into the first-dimension gel, demonstrating the presence of $\mathrm{vWf}$ in this complex. 
A
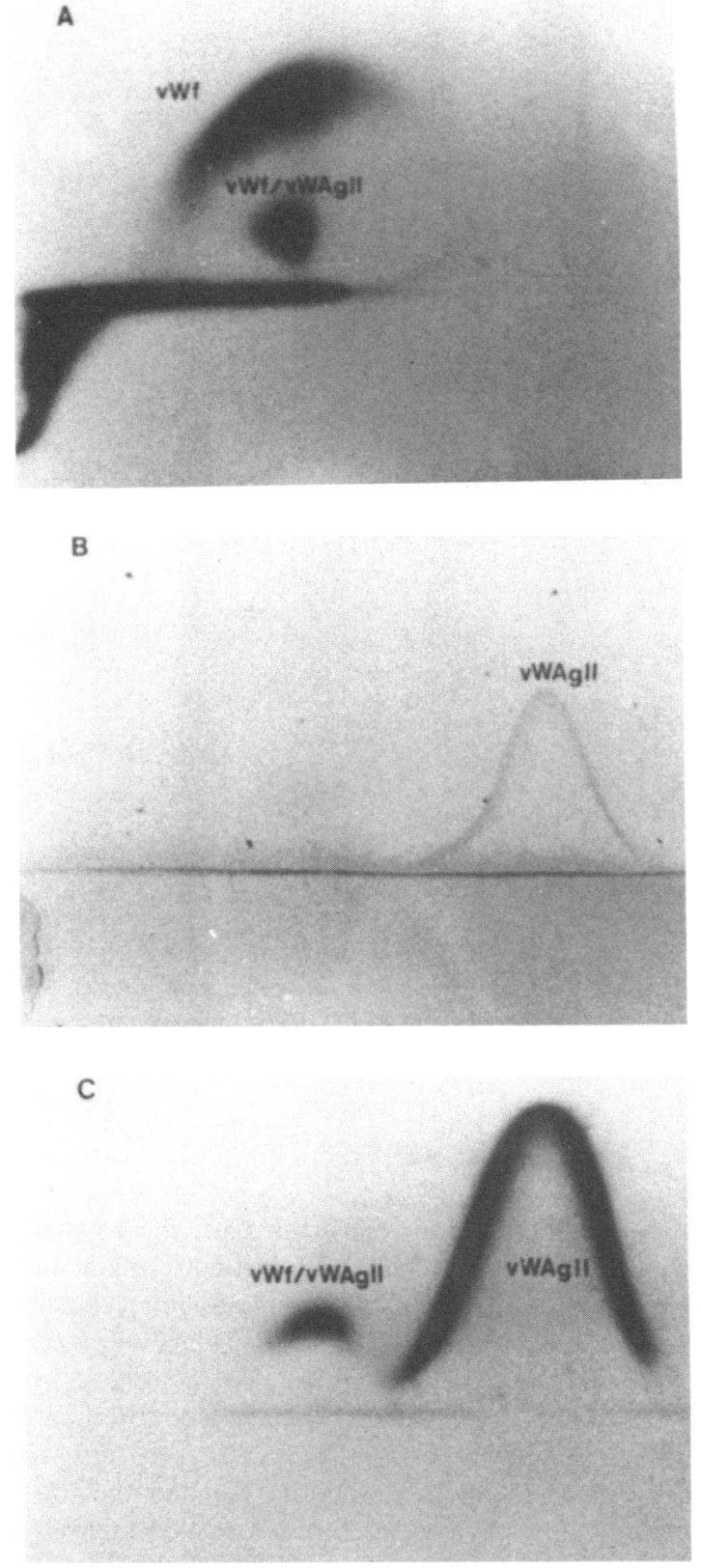

Figure 6. Localization of $\mathrm{vWf}$ epitopes in the $\mathrm{vWf} / \mathrm{vW}$ AgIl complex. Crossed immunoelectrophoresis was performed, as described in Fig 5. Nonradiolabeled endothelial cell lysate was separated in the first dimension and then electrophoresed into unlabeled antisera to $\mathrm{vW}$ AgII containing radiolabeled monoclonal IgG (AVW1) directed against vWf $\left(2 \times 10^{6}\right.$ counts/plate $)$. Radiolabeled antibody directed against vWf precipitated with free $\mathrm{vWf}$ and the $\mathrm{vWf} / \mathrm{vW}$ AgII complex $(A)$. vW AgII was visualized on the same slide by Coomassie blue staining $(B)$. The same sample, assessed using radioiodinated antibodies to $\mathrm{vW}$ AgII, demonstrated the presence of $\mathrm{vW}$ AgII epitopes in the $\mathrm{vWf} / \mathrm{vW}$ AgII complex $(C)$.

electrophoresis patterns of endothelial cell lysates against antisera to vW AgII demonstrate that vW AgII forms immunoprecipitin lines of complete identity with the complex. The complex can be shown to contain both vW AgII and vWf by using crossed immunoelectrophoresis during which antibodies to vWf both specifically radiolabel the complex (Fig. 6) and

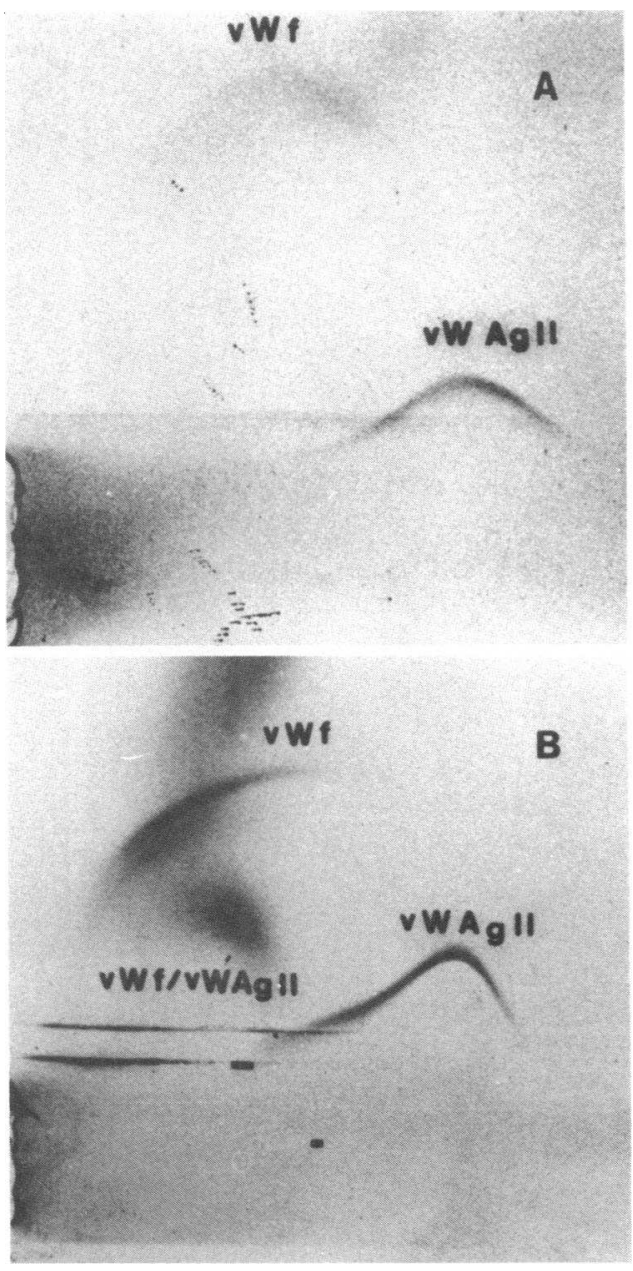

Figure 7. Crossed immunoelectrophoresis of endogenously labeled endothelial cell lysate harvested in the absence $(A)$ or presence $(B)$ of $1 \mathrm{mM}$ PMSF. With PMSF, the vWf/vW AgII complex is detected by this method. In the absence of PMSF, the complex is undetectable, suggesting a susceptibility to serine protease activity.

remove it (Fig. 5) from immunoprecipitin patterns generated with antisera against $\mathrm{vW}$ AgII. Large adherent glycoproteins do not appear to play a role in the formation of this complex. Using crossed immunoelectrophoresis, the vWf/vW AgII complex can also be shown to be distinct from free vWf (Figs. 4

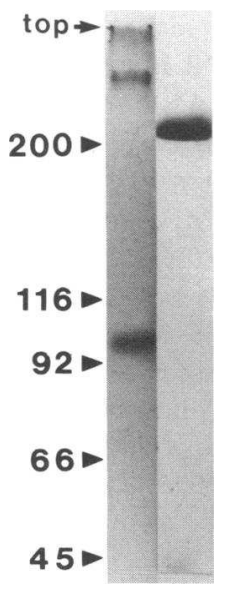

Figure 8. Molecular weight estimations of endothelial cell vWf and $\mathrm{vW}$ AgII present in the complex. Endogenously labeled endothelial cell lysate was subjected to crossed immunoelectrophoresis. The gel was washed, autoradiographed, and immunoprecipitin arcs excised and subjected to SDS-PAGE with $\beta$-mercaptoethanol. Molecular weight markers were visualized with Coomassie blue. Radiolabeled proteins were detected by autoradiography. The left lane demonstrates the reduced vWf and vW AgII complex. The molecular weight estimate for $\mathrm{vW}$ AgII was 98,000 and for vWf, 260,000 . The mobility of reduced plasma $v W f$ is shown on the right $(220,000 \mathrm{~mol} w t)$. All measurements are $\times 1,000$. 


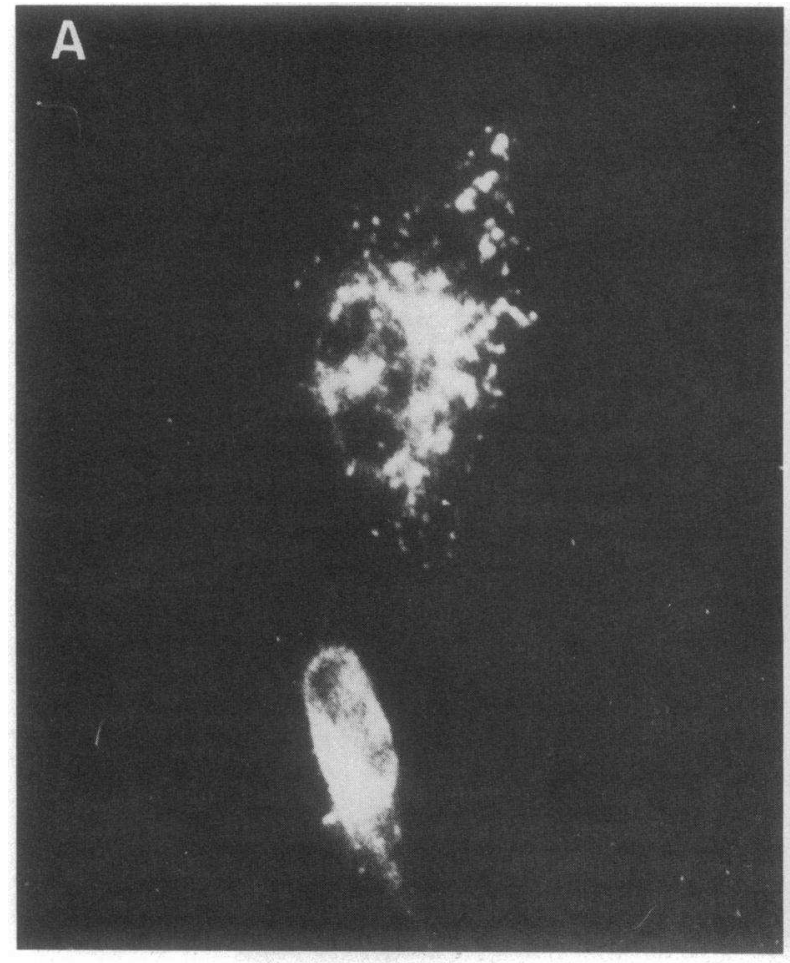

Figure 9. Immunofluorescent staining of $\mathrm{vWf}$ and $\mathrm{vW}$ AgII in endothelial cells. Double label immunofluorescence localization of $\mathrm{vWf}$ and vW AgII was performed by incubating fixed endothelial cells with murine monoclonal antisera to vWf and immunopurified rabbit IgG to vW AgII. Fluorescence labeling was with fluorescein-conju-

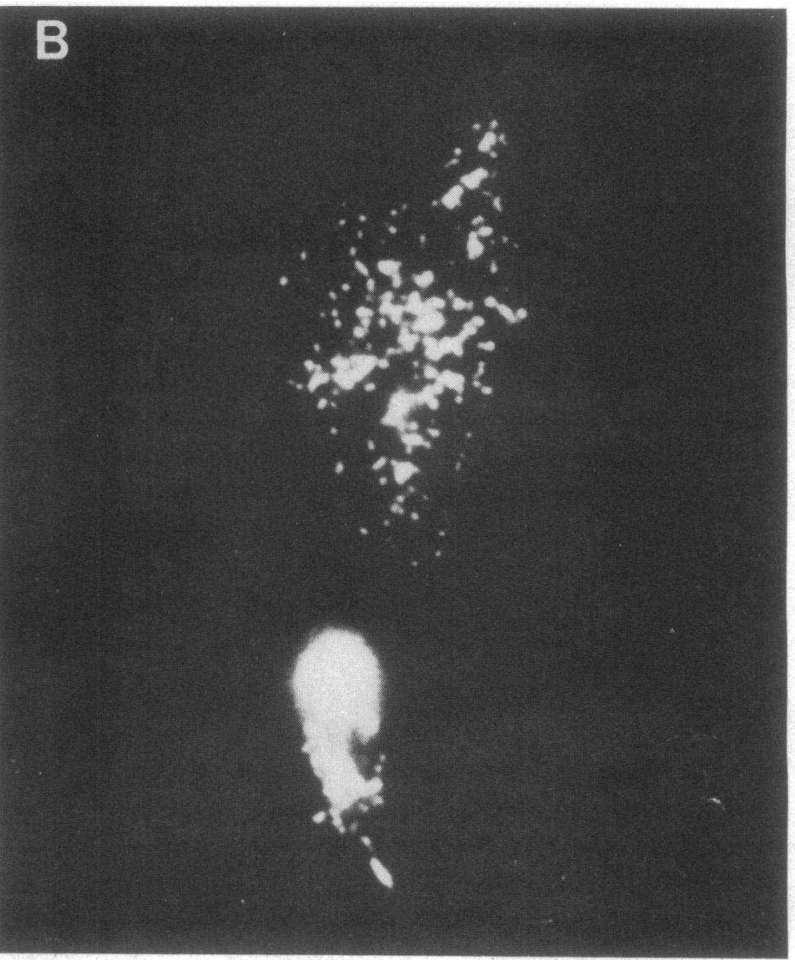

gated anti-rabbit IgG and rhodamine-conjugated anti-mouse IgG. Perinuclear fluorescein and fluorescence in organelles may be seen with fluorescein localization of $\mathrm{vW} \mathrm{AgII}(A)$. Rhodamine fluorescence colocalized $\mathrm{vWf}$ to the same organelles $(B)$. and 5) by incorporating precipitating antisera to vWf into a second strip of agarose above that containing antibodies to vW AgII (Fig. 5).

The vWf/vW AgII complex appears to be sensitive to serine proteases as it is not stable in the absence of PMSF, an inhibitor directed against this class of proteases (Fig. 7).

If $\mathrm{vW}$ AgII and $\mathrm{vWf}$ were both present in Weibel-Palade bodies, then insoluble material from the detergent lysis of these organelles might account for an apparent complexing of vW AgII with vWf. However, the lack of sedimentation of $\mathrm{vWf} / \mathrm{vW}$ AgII complex by ultracentrifugation indicated that this complexing did not occur.

$\left[{ }^{35}\right.$ S]Methionine-labeled immunoprecipitates of $\mathrm{vWf}$ and vW AgII demonstrate synthesis of these molecules in endothelial cells. Reduction of the complex with SDS and $\beta$-mercaptoethanol yields ${ }^{35} \mathrm{~S}$-labeled bands on SDS-PAGE that agree in molecular weight with radiolabeled $\mathrm{vWf}$ and $\mathrm{vW}$ AgII produced by independent methods (14) (Figs. 1, 2, and 8).

Even though $\mathrm{vW}$ AgII is separated from the vWf protein before secretion and may be found free within endothelial cells, molecular weight estimates do not support the possibility that vW AgII is the 40,000-mol-wt fragment released from the 260,000-mol-wt vWf precursor (14). Likewise, no very large precursor forms of $\mathrm{vWf}$ have been reported other than the 260,000 -mol-wt precursor to $\mathrm{vWf}(14,24)$. This does not exclude, however, the possibility that vW AgII could be a precursor piece of $\mathrm{vWf}$, since molecular weight estimates above 200,000 generated by extrapolation decrease in accuracy in the high-molecular-weight ranges.
Observations presented here resolve, in part, the enigma of the absence of two immunochemically distinct proteins in a single genetic disorder. Their relationship was intracellular rather than extracellular. Our recent work $(6,7)$ has suggested a fundamental association between these two molecules. In vivo release by DDAVP, for example, results in a concomitant release of $\mathrm{vW}$ AgII and vWf (7). Like vWf, vW AgII is synthesized in cultured human umbilical vein endothelium (7). Levels of circulating vW AgII are linearly related to levels of vWf in normal individuals and in individuals with Type I von Willebrand's disease (6). However, in individuals with Types IIA or IIB von Willebrand's disease, in which the multimeric composition of $\mathrm{vWf}$ is abnormal, the levels of $\mathrm{vW}$ AgIl are not decreased along with those of vWf but are within normal limits (6). The complex between vW AgII and vWf in endothelial cells demonstrates this association. Future studies, however, will be necessary to characterize the significance of the vWf/vW AgIl complex in the synthesis of vWf and, perhaps, in the pathophysiology of von Willebrand's disease.

\section{Acknowledgments}

The authors wish to thank John Schullek and Mike Corcoran for expert technical assistance.

Dr. McCarroll was supported by Department of Health and Human Services Institutional Training Grant HL-07209 and a Postdoctoral Fellowship of the American Heart Association-Wisconsin Affiliate.

This work was supported, in part, by grants HL-29036, HL-30052, HL-17419, and HL-29815 of the National Heart, Lung and Blood Institute. 


\section{References}

1. Zimmerman, T. S., and Z. M. Ruggeri. 1983. von Willebrand's disease. Clin. Haematol. 12:175-200.

2. Bloom, A. L. 1980. The von Willebrand syndrome. Semin. Hematol. 17:215-227.

3. Hoyer, L. W. 1981. The factor VIII complex: structure and function. Blood. 58:1-13.

4. Montgomery, R. R., and T. S. Zimmerman. 1978. von Willebrand's disease antigen II: a new plasma and platelet antigen deficient in severe von Willebrand's disease. J. Clin. Invest. 61:1498-1507.

5. Montgomery, R. R., and J. Johnson. 1982. Specific factor VIIIrelated antigen fragmentation: an in vivo and in vitro phenomenon. Blood. 68:930-939.

6. McCarroll, D. R., Z. M. Ruggeri, and R. R. Montgomery. 1984. Correlation between circulating levels of von Willebrand's disease antigen II and von Willebrand factor: discrimination between Type I and Type II von Willebrand's disease. J. Lab. Clin. Med. 103:704711.

7. McCarroll, D. R., Z. M. Ruggeri, and R. R. Montgomery. 1984. The effect of DDAVP on plasma levels of von Willebrand's antigen II in normal individuals and patients with von Willebrand's disease. Blood. 63:532-535.

8. Scott, J. P., and R. R. Montgomery. 1981. Platelet von Willebrand's antigen II: active release by aggregating agents and a marker of platelet release reaction in vivo. Blood. 58:1075-1080.

9. Sakariassen, K. S., P. A. Bolhuis, and J. J. Sixma. 1979. Human blood platelet adhesion to artery subendothelium is mediated by factor VIII von Willebrand factor bound to the subendothelium. Nature (Lond.). 279:636-638.

10. Zimmerman, T. S., L. W. Hoyer, L. Dickson, and T. S. Edgington. 1975. Determination of the von Willebrand's disease antigen (factor VIII-related antigen) in plasma by quantitative immunoelectrophoresis. J. Lab. Clin. Med. 86:152-159.

11. Weiss, H. J., J. Rogers, and H. Brand. 1973. Defective ristocetin-induced platelet aggregation in von Willebrand's disease and its correction by factor VIII. J. Clin. Invest. 52:2697-2707.

12. Jaffe, E. A., L. W. Hoyer, and R. L. Nachman. 1973. Synthesis of von Willebrand antihemophilic factor antigen by cultured human endothelial cells. Proc. Natl. Acad. Sci. USA. 71:1906-1909.

13. Lynch, D. C., R. Williams, T. S. Zimmerman, E. P. Kirby, and D. M. Livingston. 1983. Biosynthesis of subunits of factor VIIIR by bovine aortic endothelial cells. Proc. Natl. Acad. Sci. USA. 80: 2738-2742.

14. Wagner, D. D., and V. J. Marder. 1983. Biosynthesis of von Willebrand protein by human endothelial cells. J. Biol. Chem. 258: 2064-2067.

15. Nachman, R., R. Levine, and E. A. Jaffe. 1977. Synthesis of factor VIII antigen by cultured guinea pig megakaryocytes. J. Clin. Invest. 60:914-921.

16. Chan, V., and T. K. Chan. 1982. Characterization of factor VIII related protein synthesized by human endothelial cells: a study of structure and function. Thromb. Haemostasis. 48:177-181.

17. Wagner, D. D., J. B. Olmsted, and V. J. Marder. 1982. Immunolocalization of von Willebrand protein in Weibel-Palade bodies of human endothelial cells. J. Cell Biol. 95:355-360.

18. Jaffe, E. A. 1980. Culture of human endothelial cells. Fed. Proc. 12(Suppl. 1):49-53.

19. Maciag, T., J. Cerundolo, S. Ilsley, P. R. Kelley, and R. Forand. 1979. An endothelial cell growth factor from bovine hypothalamus: identification and partial characterization. Proc. Natl. Acad. Sci. USA. 76:5674-5678.

20. Schullek, J., J. Jordan, and R. R. Montgomery. 1984. Interaction of von Willebrand factor with human platelets in the plasma milieu. J. Clin. Invest. 73:421-428.

21. McConahey, P. J., and F. T. Dixon. 1980. Radioiodination of proteins by the use of chloramine-T method. Methods Enzymol. 70: 210-213.

22. Laemmli, U. K. 1970. Cleavage of structural proteins during the assembly of the head of bacteriophage T-4. Nature (Lond.). 227: 680-685.

23. Kunicki, T. J., A. T. Nurden, D. Pidard, N. J. Russell, and J. P. Caen. 1981. Characterization of human platelet glycoprotein antigens giving rise to individual immunoprecipitates in crossed immunoelectrophoresis. Blood. 58:1190-1197.

24. Chan, V., and T. K. Chan. 1983. Cell-free translational factor VIII related protein. Thromb. Haemostasis. 50:18. (Abstr.) 